\title{
Particle Swarm Optimization based Control Setting of TCSC for Improving Reliability of Composite Power System
}

\author{
Venkata Padmavathi.S \\ Assistant Professor, \\ EEE Dept, GITAM University \\ Hyderabad, A.P, India
}

\author{
Saratkumar Sahu, PhD. \\ Professor \\ M.V.G.R College of Engg \\ Vizianagaram, A.P, India
}

\author{
A.Jayalakshmi, PhD. \\ Associate Professor \\ JNTU Hyderabad \\ A.P, India
}

\begin{abstract}
With the introduction of competition in the existing electrical market, it became necessary to increase the capability of transmission of power through the existing transmission lines. This paper describes a method of improving reliability of composite power system by increasing transmission system capability using FACTS devices. The utilization of FACTS [1] technologies will have a significant positive impact on power system performance in terms of reliability. Considerable efforts have been made in the past for developing techniques to evaluate composite power system reliability.

The proposed method is based on the probabilistic approach to determine the load point reliability indices in a practical system. Composite system reliability can be increased by adjusting the settings of the FACTS device (such as reactance, phase angles, reactive power injection) with respect to the system parameters. In this paper, the settings of TCSC are obtained using Particle Swarm Optimization technique. The settings thus obtained are used for enhancing the transmission power capacity while improving the composite power system reliability. The proposed scheme is tested on Roy Billinton Test System (RBTS).
\end{abstract}

Keywords- Flexible AC Transmission System (FACTS), Thyristor controlled series capacitors (TCSC), Particle Swarm Optimization technique (PSO), Loss of load probability (LOLP)

\section{INTRODUCTION}

The function of a power system is to supply electrical energy on demand, economically and within acceptable levels of reliability and service quality. The basic element in power system planning is to determine of how much generation capacity is required giving a reasonable assurance of satisfying the load requirements. A wide range of probabilistic techniques have been developed for the evaluation of system behavior. These include techniques for reliability evaluation, and probabilistic load flow.

All the techniques developed so far are concerned with future behavior of the component or system. In most of the cases, the problem cannot be defined as deterministic, but as stochastic in nature i.e., it varies randomly with time.

The fundamental and basic concept behind each of these developments is the need to recognize that power systems behave stochastically and all input and output states and event parameters are probabilistic variables. Probabilistic techniques have been developed to recognize not only the severity of a state or an event and its impact on system behavior and operation, but also the likelihood or probability of its occurrence.
FACTS devices are well known for their voltage control, reactive power compensation and power flow control applications. FACTS technologies [1] are proven solutions to rapidly enhancing reliability and upgrading transmission capacity on long term and cost effective basis. These are effective where new transmission line construction is not feasible. FACTS [1] are high speed, reliable, power electronic controllers.

In this paper a simple test system Roy Billiton [2] is considered and DC load flow was run and the Loss of load probability calculation was done using the probabilistic method. For studying the effect of FACTS controllers on LOLP, TCSC, which is a series controller, is incorporated in the selected lines and the effect on LOLP was observed. The study was done by installing a single TCSC at a line and running the load flow for testing the effect of the variation in the system impedance through TCSC. Both single and double line contingencies are considered for the evaluation of LOLP.

Though using AC load flow analysis gives an accurate result, it is rather time consuming, so for cases where time of execution is of more concern, one can go for approximation of the results and hence chose DC load flow. But the DC load flow has a disadvantage of that it cannot include the voltage constraints. PSO [7] is used in estimating the optimal control setting of the TCSC to be incorporated in the lines. Several possible combinations with the use of TCSC in the system were tried and the variations in the LOLP of the system are observed. The reason for choosing PSO is that it is very efficient algorithm in converging towards the global solution that optimizes the function. The reason for choosing TCSC among various FACTS devices is that, it can be easily modeled as a reactance in series with the line reactance in the equivalent circuit.

\subsection{Reliability Definition}

The term reliability [4] has a very wide range of meanings. In general it is defined as the probability of a device performing its purpose adequately for the period of time intended under the operating conditions encountered.

\subsection{Need for Reliability Evaluation}

In our modern society, professional engineers are responsible for the planning, design, manufacture, operation of products and system ranging from the simple product to the complex system. The failure in any product causes inconvenience and irritation and a severe impact on society and its environment. The users expect the products and systems they purchase are reliable and safe. Engineers always strive to operate systems that are relatively free from failures. The only way in which all these competing and diverse uncertainties can be weighted 
together in an objective and consistent fashion is by the use of quantitative reliability evaluation techniques.

\section{COMPOSITE POWER SYSTEM RELIABILITY EVALUATION}

The total problem of assessing the adequacy of the generation and bulk power transmission systems in regard to provide suitable supply at the terminal stations can be designed as composite power system reliability evaluation[4][8].

Composite Probability, $\mathrm{P}_{\mathrm{c}}=\mathrm{P}_{\mathrm{g}} * \mathrm{P}_{\mathrm{t}}$

Where,

$\mathrm{P}_{\mathrm{g}}=$ probability of generating unit

$\mathrm{P}_{\mathrm{t}}=$ probability of transmitting unit

\subsection{Generation System Reliability}

The total system generation is examined to determine its adequacy to meet the total system load requirement. This is usually termed "generation capacity reliability evaluation". In this study the transmission system and its ability to move the generation energy to the consumer load points is ignored. The only concern is in estimating the necessary generation capacity to satisfy the system demand and to have sufficient capacity to satisfy the corrective and preventive maintenance on the generation facilities.

\subsubsection{Generation system model}

The generating units are divided into two groups: the conventional units, which may be controlled and scheduled, and the non-conventional units, which generally can be scheduled. For the generation system model the generation outages are treated individually and the model is evaluated.

The generation system model failure probability computed with the known data by

- $\quad$ Probability of generating unit $\left(\mathrm{P}_{\mathrm{g}}\right)=\mathrm{nc}_{\mathrm{r}} \mathrm{p}^{\mathrm{r}} \mathrm{q}^{\mathrm{n}-\mathrm{r}}$

Where,

$\mathrm{n}$ is number of units.

$p$ is availability of each unit.

$\mathrm{q}$ is unavailability of each unit

Using the above said formulas the generation system model is computed.

\subsection{Transmission System Reliability}

Transmission system deals with the transfer of electric power to the consumers in a reliable manner.

An electric supply system consists of three principal components viz. the power station, transmission lines and distribution system. The electric power produced at the power station is transmitted over large distances to the load centre by transmission lines. The transmission system associates with itself the substation, switching station and their associated components such as current transformers, potential transformers, breakers, relays, bus bars, reactors, capacitor banks, transmission lines.

The bus scheme or the configuration of components along with bus bars is to be effectively planned for reliable supply of power to consumers.

\subsubsection{Transmission System Model}

Transmission system model failure probability is computed by using

Probability of transmitting unit $\left(\mathrm{P}_{t}\right)=n c_{r} p^{r} q^{n-r}$

Where,

n-number of lines

r-number of available lines p-availability of each line

q-unavailability of each line

\section{THYRISTOR CONTROLLED SERIES CAPACITOR}

TCSC [1] is a capacitive reactance compensator which consists of a series capacitor banks shunted by a thyristor controlled reactor in order to provide a smoothly variable series capacitive reactance.

A variable reactor such as a thyristor controlled reactor (TCR) is connected across a series capacitor. When the TCR firing angle is $180^{\circ}$ the reactor becomes non-conducting and series capacitor has its normal reactance. As the firing angle reduces to less than $180^{\circ}$ the capacitive reactance increases. When TCR firing. angle is $90^{\circ}$ the reactor becomes fully conducting and the total reactance becomes inductive because the reactor impedance is designed to be much lower than the series capacitor impedance with firing angle $90^{\circ}$ to limit the fault current.

The TCSC is employed in the system to adjust the transmission in feed impedance and therefore increase transmission system capacity without increasing the system fault current levels.

The capacitor bank is provided with a parallel thyristor controlled inductor that circulates current pulses which add in phase with the line current. This boosts the capacitor voltage.

The TCSC may have one of the two possible characteristics: capacitive or inductive, respectively to decrease or increase the impedance of the branch. It is modeled with variable series reactance. Its value is function of the reactance of the line $X_{L}$ where the device is located [6]. It is in the range $-0.8 \mathrm{X}_{\mathrm{L}}<\mathrm{X}_{\mathrm{TCSC}}<0.2 \mathrm{X}_{\mathrm{L}}$

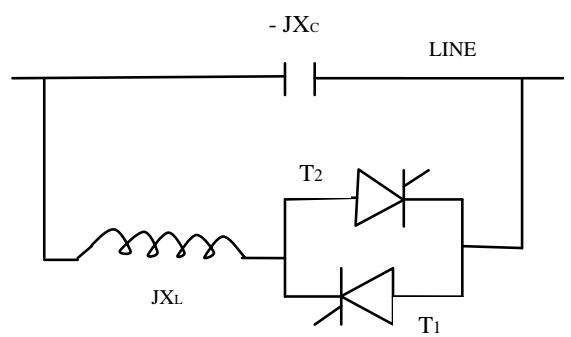

Fig1: Simplified TCSC model

\section{OVER VIEW OF PSO}

Particle swarm optimization (PSO) is an evolutionary computation technique [7] developed by Dr. Eberhart and Dr. Kennedy in 1995, inspired by social behavior of bird flocking or fish schooling.

Similar to genetic algorithms (GA), PSO [9] is a population based optimization tool. The system is initialized with a population of random solutions and searches for optima by updating generations. However, unlike GA, PSO has no evolution operators such as crossover and mutation. In PSO, the potential solutions, called particles are "flown" through the problem space by following the current optimum particles. Compared to GA, PSO has the advantages of easy implementation and less number of parameters to adjust. PSO has been successfully applied in many areas: function optimization, artificial neural network training, fuzzy system control, and other areas where genetic algorithm can be applied. 


\section{METHODOLOGY}

\subsection{Probabilistic Elements Model}

The forced outage rates for generating units, which described the outage capacity density function for units when two state models were used (i.e. unit availability and unavailability). The same type of probabilistic description will be used for other transmission elements in transmission system reliability.

Each transmission element is described adequately by two state models and associated Forced Outage Rates (FOR). For simplicity two state models will be used throughout.

\subsection{Basic Philosophy}

Given that each element, $V_{m}, m=1,2 \ldots \ldots \ldots . ., E$, in the system under study [3] can reside in either the " 0 " state, with probability $\mathrm{q}_{\mathrm{m}}$, in which it has no capacity and is out of service, or the " 1 " state, with probability $\mathrm{p}_{\mathrm{m}}$, in which it has capacity $\mathrm{Cm}$ and is in service, the system will have $2^{\mathrm{E}}$ distinct capacity states $X_{i}, i=1,2 \ldots \ldots \ldots \ldots \ldots 2^{\mathrm{E}}$, Take the 6bus RBTS system it has 11 elements: 2 generators and 9 lines so the system can reside in any one of $2^{11}$ different capacity states $X_{\mathrm{i}}$. Obviously the upper and lower limiting states denoted by $\bar{X}$ $=(1,1,1,1,1,1,1,1,1,1,1)$ and state $\mathrm{X}=(0,0,0,0,0,0,0,0,0,0,0)$. Associated state probabilities with each of the $2^{\mathrm{E}}$ states is a probability $\mathrm{f}\left(\mathrm{X}_{\mathrm{i}}\right)$ that it will occur; for example the probability ,f(x), that the 6 bus system will reside in upper limiting state is

$\mathrm{f}(\bar{X})=\prod_{m=1}^{E} p_{m}=\mathrm{p}_{1} \mathrm{p}_{2} \mathrm{p}_{3} \mathrm{p}_{4} \mathrm{p}_{5} \mathrm{p}_{6} \mathrm{p}_{7} \mathrm{p}_{8} \mathrm{p}_{9} \mathrm{p}_{10} \mathrm{p}_{11}$

the probability for lower limiting states is

$$
\overline{\mathrm{f}(\mathrm{X})}=\prod_{m=1}^{E} q_{m}=\mathrm{q}_{1} \mathrm{q}_{2} \mathrm{q}_{3} \mathrm{q}_{4} \mathrm{q}_{5} \mathrm{q}_{6} \mathrm{q}_{7} \mathrm{q}_{8} \mathrm{q}_{9} \mathrm{q}_{10} \mathrm{q}_{11}
$$

The probability for that system will reside in any state

$\mathrm{f}\left(\mathrm{x}_{\mathrm{i}}\right)=\Pi \mathrm{f}\left(\mathrm{V}_{\mathrm{m}}\right)$

Where $\mathrm{f}\left(\mathrm{V}_{\mathrm{m}}\right)=\mathrm{p}_{\mathrm{m}}$ if $\mathrm{V}_{\mathrm{m}}=1$

$\mathrm{f}\left(\mathrm{V}_{\mathrm{m}}\right)=\mathrm{q}_{\mathrm{m}} \quad$ if $\mathrm{V}_{\mathrm{m}}=0$

Decompose the system states into acceptable and unacceptable states, for those unacceptable states calculate the LOLP

LOLP $=\Sigma \mathrm{f}\left(\mathrm{x}_{\mathrm{i}}\right) \quad \mathrm{x}_{\mathrm{i}}=$ all unacceptable states.

\subsection{Problem Formulation}

Based on the DC power flow model, the base case powers are obtained. Now by modeling single line contingency analysis and double line contingency analysis obtain the unacceptable states, these are the states at which the load does not meet the demand. So for the unacceptable states calculate the LOLP. The line power flow can be calculated by using the DC power flow equation as shown below.

$$
P_{i j}=1 / X_{i j}\left(\theta_{i}-\theta_{j}\right)
$$

Where, $P_{i j}$ is the power flow between the buses $i$ and bus $j$.

$\mathrm{X}_{\mathrm{ij}}$ is line reactance.

$\theta_{\mathrm{i}}, \theta_{\mathrm{j}}$ are the angles at buses $\mathrm{i}$ and $\mathrm{j}$.

For a given positive line flow limit $\mathrm{P}_{\mathrm{ij}}{ }^{\mathrm{max}}$, which is assumed to be equal to the line MVA rating.

The objective of the problem is to maximize the power flow in the considered DC model. To maximize the power flow, TCSC is used to vary the reactance of the line to which it is introduced. The TCSC is introduced into the line with the maximum value of power flow obtained in transmission line.

The problem is solved as a minimization problem with the objective of maximizing the power flow as given below,

\subsection{Algorithm}

$$
\operatorname{Max}\{\operatorname{Pij}\}=\min \left\{1 /\left(1+\mathrm{P}_{\mathrm{ij}}\right)\right\}
$$

The step by step algorithms to solve this problem are as follows.

Step.1 Start

Step. 2 Read the system data

Step.3 Formulate the DC power flow solutions

Step.4 Calculate the line flow values

Step.5 By considering single and double line contingencies obtains the unacceptable states and calculates LOLP.

Step.6 Using PSO locates randomly the TCSC in a line and estimate the reactance value

Step.7 Run from step. 3 to step. 5 for the new bus data with the introduction of TCSC

Step.8 Print results

\section{RESULTS \& DISCUSSION}

The simulation for the Roy Billinton Test System [2] is studied with single TCSC incorporated to enhance the power flow and simultaneously adjust the line reactance with in the line limit. The simulation is carried out in MATLAB version 7.0 for Windows environment. The results are as shown in table6.1. From the table6.1 it is clear that by placing TCSC in transmission system, the failure probability is reducing. We know that if the failure probability reduces the reliability will improve. So by inclusion of FACTS in transmission lines the power transmission capacity is improved. TCSC is installed to increase the transmission capability. By using PSO technique the optimal setting of TCSC is arrived. The optimal locations are found at lines 1,2,6,7 and other lines are not feasible to incorporate TCSC. If the TCSC is connected in line 1 or 6 the power flow is increased in lines connected between the buses 1 and 2 from $0.29 \mathrm{pu}$, to $0.37 \mathrm{pu}, 3$ and 5 from $0.16 \mathrm{pu}$ to $0.19 \mathrm{pu}$.If the TCSC is connected in line 2 or 7 the power flow is increased in lines connected between the buses 1 and 3 from $0.46 \mathrm{pu}$ to $0.49 \mathrm{pu}, 2$ and 4 from $0.36 \mathrm{pu}$ to $0.40 \mathrm{pu}, 1$ and 2 from $0.29 \mathrm{pu}$ to $0.33 \mathrm{pu}, 3$ and 5 from $0.16 \mathrm{pu}$ to $0.18 \mathrm{pu}, 2$ and 4 from0.35pu to $0.40 \mathrm{pu}$.and the lines are within their thermal limits. So if power transfer capability increases the loss of load probability decreases. So the reliability is improved.

Table 6.1: Generation system reliability

\begin{tabular}{|c|c|c|}
\hline State & $\begin{array}{l}\text { Capacity } \\
\text { Outage(MW) }\end{array}$ & Probability \\
\hline 1 & 0 & 0.81271400 \\
\hline 2 & 10 & 0.01658600 \\
\hline 3 & 20 & 0.07081400 \\
\hline 4 & 25 & 0.00100000 \\
\hline 5 & 30 & 0.00144520 \\
\hline 6 & 35 & 0.00002040 \\
\hline 7 & 40 & 0.06924200 \\
\hline 8 & 45 & 0.00038320 \\
\hline 9 & 50 & 0.00104930 \\
\hline 10 & 55 & 0.00000000 \\
\hline 11 & 60 & 0.00355235 \\
\hline 12 & 65 & 0.00009160 \\
\hline 13 & 70 & 0.00010096 \\
\hline 14 & 80 & 0.00221280 \\
\hline 15 & 85 & 0.00002160 \\
\hline
\end{tabular}




\begin{tabular}{|c|c|c|}
\hline 16 & 90 & 0.00004462 \\
\hline 17 & 100 & 0.00014819 \\
\hline
\end{tabular}

Table 6.2: Transmission system reliability

\begin{tabular}{|c|c|}
\hline Line no. & Probability \\
\hline 1 & 0.99829000 \\
\hline 2 & 0.99432460 \\
\hline 3 & 0.99432460 \\
\hline 4 & 0.99885975 \\
\hline 5 & 0.99885975 \\
\hline 6 & 0.99829060 \\
\hline 7 & 0.99885900 \\
\hline 8 & 0.99885900 \\
\hline 9 & 0.99885900 \\
\hline
\end{tabular}

Table 6.3: Loss of Load Probability of RBTS

\begin{tabular}{|c|c|c|}
\hline $\begin{array}{c}\text { LOLP without } \\
\text { TCSC }\end{array}$ & $\begin{array}{c}\text { LOLP with TCSC } \\
\text { at line } 1 \text { or } 6\end{array}$ & $\begin{array}{c}\text { LOLP with TCSC } \\
\text { at line } 2 \text { or } 7\end{array}$ \\
\hline 0.0093 & 0.007 & 0.008 \\
\hline
\end{tabular}

PSO parameters: $\quad$ Pop size $=20$

Learning factors $\mathrm{C}_{1}=2 \mathrm{C}_{2}=2$

Max velocity $\mathrm{V}_{\max }=10$

Max iterations $=100$

\section{CONCLUSION}

An optimization model is proposed to evaluate the composite power system reliability incorporating TCSC. The DC Power flow programming model is used in the reliability evaluation. The reliability indices are calculated on 6-bus RBTS using proposed algorithm. The installation of TCSC shows considerable positive impact on power system reliability. The composite power system reliability was improved by employing the TCSC in the transmission line by using PSO technique in this work. The results of this model would be useful for planning and future expansion.

\section{REFERENCES}

[1] N.G. Hingorani \& L. Gyugyi New York: IEEE, 2000.Understanding FACTS, Concepts \& Technology of Flexible AC Transmission Systems.

[2] Roy Billinton \&Yu cui IEEE 2002.'Reliability Evaluation of Composite Electric power systems incorporating FACTS".

[3] R.L.Sullivan, "Power system planning", Mc Graw Hill International Book Company, 1997.

[4] Roy Billiton \& Ronald N Allan, "Reliability Evaluation of power systems", Pitman-1984.

[5] R.Billinton, S.Kumar, N. Chowdhury, K.Chu, K.Debnath, L.Goel, E.Khan, P.Kos, G.Nourbakhsh, J.Oteng-Adjei, "A Reliability Test System for Educational Purposes-Basic data 1989 IEEE

[6] S.Gerberi, R.Chercaoui, and A.J.Germond, "Optimal Location of FACTS Devices to Enhance Power System Security" IEEE 2003

[7] James Kennedy and Russell Eberhart, "Particle Swarm Optimization”, IEEE Conf. 1995, pp. 1942-1948.

[8] Kumar T.S, Sankar. V, "Reliability improvement of composite electric power system using Unified Power Flow Controller" 2011 IEEE

[9] Sharma, N.K,Suresh Babu, D,Choube, S.C. “Application of particle swarm optimization technique for reactive power optimization" Advances in Engineering, Science and Management (ICAESM), 2012 International Conference.

[10] Gerbex. S, Cherkaoui.R, Germond A.J. "Optimal location of FACTS devices to enhance power system security" Power Tech Conference Proceedings, 2003 IEEE Bologna , and Volume: 3 